\title{
Efeito da aplicação de vácuo no desempenho de diferentes modelos de gotejadores sob duas condições de textura de solo
}

\author{
Rubens D. Coelho ${ }^{1}$, Jorge L. C. dos Santos Júnior ${ }^{2}$, Christian J. Mendoza ${ }^{3}$, \\ Pedro H. P. Ribeiro ${ }^{4}$, Fernando N. Cunha ${ }^{5} \&$ Marconi B. Teixeira ${ }^{5}$
}

\begin{abstract}
RESUMO
Na irrigação localizada com gotejadores posicionados de modo subsuperficial há o risco potencial de partículas de solo serem succionadas através do orifício de saída de água, em virtude da ocorrência de vácuo podendo resultar no entupimento dos mesmos. Objetivou-se, com este trabalho, avaliar o efeito da aplicação de vácuo no desempenho de diferentes modelos de gotejadores sob duas condições de textura de solo e posicionados de modo subsuperficial. Os tratamentos consistiram da aplicação dos níveis de sucção de -10, -15, -20 e -40 kPa, em solos de textura arenosa e argilosa, em 23 modelos de gotejadores usados com mais de 1 ano de funcionamento. O desempenho dos emissores no gotejamento subsuperficial foi influenciado pela textura do solo. De modo geral, em $80 \%$ dos emissores o vácuo de -40 kPa proporcionou obstrução nos emissores e redução da vazão, em ambas as texturas de solo. A maior redução de uniformidade de aplicação de água ocorreu com o modelo Irrimon Irridrip Plus 2,5 $\mathrm{L} \mathrm{h}^{-1}$ na condição de solo arenoso e aplicação de 40 kPa de sucção.
\end{abstract}

Palavras-chave: gotejamento subsuperficial, obstrução, redução de vazão

\section{Effect of vacuum on the performance of different models of drippers under two conditions of soil texture}

\begin{abstract}
In drip irrigation with emitters positioned subsurfacely there is the potential risk of soil particles being suctioned through the water outlet port, due to the occurrence of vacuum which may result in clogging of drippers. The objective of this study was to evaluate the effect of vacuum on the performance of different models of subsurface positioned drippers under two conditions of soil texture. The treatments consisted of applying suction levels of $-10,-15,-20$ and $-40 \mathrm{kPa}$ in sandy and clayey soils in 23 models of used drippers with more than 1 year of operation. The performance of the subsurface drip emitters was influenced by soil texture. Overall, in $80 \%$ of drippers , $-40 \mathrm{kPa}$ vacuum caused the obstruction of emitter and reduced flow in both soils. The largest reduction of uniformity of water application was observed in model Irrimon Irridrip Plus $2.5 \mathrm{~L} \mathrm{~h}^{-1}$ in sandy soil and application of $40 \mathrm{kPa}$ suction.
\end{abstract}

Key words: subsurface drip, obstruction, flow rate reduction

' ESALQ/ USP, Departamento de Engenharia de Biossistemas (LEB). Av. Pádua Dias, 11, CEP 13418-900, Piracicaba, SP. Fone: (19) $3447-8542$. E-mail:rdcoelho@usp.br; christianmendozac@hotmail.com

2 UEMA, Cidade Universitária Paulo VI, C. P. 09, São Luís, MA. Fone: (98) 3244-0419. E-mail: christianmendozac@gmail.com

${ }^{3}$ Instituto Federal de Educação, Ciência e Tecnologia Baiano - Câmpus Valença. Rua Glicério Tavares, sn, Bate Quente, CEP 45400-000, Valença, BA. Fone: (75) 3641-3511. E-mail:jorgecopquer@gmail.com

${ }^{4}$ UAEA/UFCG. Av. Aprígio Veloso, 882, Bodocongo. CEP 58429-140. Fone: (64) 8112-7457. E-mail: pedroirri@gmail.com

${ }^{5}$ Instituto Federal de Educação, Ciência e Tecnologia Goiano - Câmpus Rio Verde. Rod. Sul Goiana, Km 01, Zona Rural, C. P. 66, CEP 75901-970, Rio Verde, GO. Fone: (64) 3620-5636. E-mail: marconibt@gmail.com; fernandorcfilho@hotmail.com 


\section{INTRODUÇÃO}

O sistema de irrigação por gotejamento se caracteriza pela aplicação de água na forma de gotas diretamente sobre a superfície do solo, permitindo fornecer a água em pequenas quantidades, próximo às raízes das plantas, não molhando as entrelinhas. Com isto, o consumo de água é reduzido quando comparado a outros sistemas de irrigação. Quando bem manejada, permite uma eficiência maior de aplicação de água em consequência de um controle melhor da lâmina aplicada, menores perdas por evaporação e, praticamente, nenhuma perda por percolação e escoamento superficial (Resende et al., 2004) mas para a realização de um manejo eficiente de água é necessário que a uniformidade de aplicação de água pelos emissores seja a maior possível (Faria et al., 2004; Capra \& Scicolone, 2007).

A irrigação por gotejamento pode ser usada tanto na superfície do solo quanto enterrada recebendo, neste caso, o nome de irrigação por gotejamento subsuperficial.

Com a evolução das características hidráulicas dos emissores vem-se intensificando cada vez mais o uso do gotejamento abaixo da superfície do solo (gotejamento subsuperficial), com a alegação de se obter algumas vantagens sobre a forma tradicional (gotejamento superficial) como, por exemplo, a possibilidade de maior vida útil do equipamento e maior eficiência de uso da água (Gomes \& Sousa, 2002).

Em comparação com o superficial, o sistema de gotejamento subsuperficial tem uma série de vantagens adicionais, como aplicar água e nutrientes diretamente na zona radicular, reduzir as perdas por evaporação, evitar danos mecânicos durante as operações de cultivo e por roedores às tubulações, proporcionar maior crescimento do sistema radicular, reduzir a umidade na superfície do solo e minimizar a incidência de doenças (Camp, 1998; Silva et al., 1999).

A irrigação por gotejamento subsuperficial vem sendo comparada a outros sistemas de irrigação para diferentes tipos de cultura sendo que em todos os casos a produção é igual ou superior (Camp, 1998; Marques et al., 2006).

Estudos realizados por Sanchez-Martín et al. (2010) quanto ao padrão de distribuição de fertilizantes orgânicos via água de irrigação em sistemas de irrigação por gotejamento permitiram quantificar maior ocorrência de nitrificação em relação ao sistema de irrigação por sulco, embora a aplicação de fertilizantes orgânicos aumente a desnitrificação cuja ocorrência se deu em função da aplicação de pulsos sucessivos nas parcelas com irrigação por gotejamento ao longo do período de irrigação, permitindo o reumedecimento do solo seco alterando-se, assim, o padrão de emissão de $\mathrm{N}_{2} \mathrm{O}$ e $\mathrm{NO}$.

A irrigação por gotejamento subsuperficial é muito pouco divulgada e empregada no Brasil, possivelmente pelas limitações que apresenta, como problemas de entupimento, baixa disponibilidade no mercado de equipamentos adequados e a carência de pesquisas indicando a viabilidade técnica e econômica (Dalri \& Cruz, 2002).

O gotejamento subsuperficial está sujeito à maioria dos problemas que ocorrem no gotejamento superficial somando-se, ainda, a obstrução dos emissores por sucção de partículas sólidas e a possibilidade de penetração do sistema radicular das culturas e plantas daninhas nos emissores, prejudicando a vazão dos emissores à jusante do ponto de intrusão bem como desequilíbrio hidráulico ao sistema (Batista et al., 2008; Dalri \& Cruz, 2008) e consequentemente afeta a uniformidade de aplicação de água (Solomon, 1985; Capra \& Scicolone, 2004; Yavuz et al., 2010).

A irrigação localizada subsuperficial apresenta o risco inerente das partículas do solo serem succionadas através do orifício de saída de água dos gotejadores em virtude da ocorrência de vácuo, podendo resultar no entupimento dos gotejadores (Jun et al., 2007; Zhang et al., 2007; Coelho et al., 2009).

A ocorrência de vácuo na parcela de irrigação está relacionada tanto ao fenômeno de transientes hidráulicos que podem ocorrer mesmo em linhas laterais niveladas quanto, também, à interrupção abrupta do sistema de irrigação em linhas laterais não niveladas. Neste último caso ocorre o succionamento de partículas sólidas da zona saturada do bulbo molhado para dentro de cada gotejador inserido nas linhas laterais de maior cota em função da drenagem da malha hidráulica através dos gotejadores localizados na parte mais baixa da área irrigada. O esvaziamento das linhas de gotejadores pode resultar em valores de pressões negativas suficientes para colapsar as linhas secundárias, de PVC, sendo imprescindível o uso de ventosas de duplo efeito nos pontos mais íngremes da área em que o sistema está instalado, a fim de prevenir a sucção e a entrada de solo na tubulação, especialmente em declives acentuados (Coelho, 2007).

O objetivo foi avaliar o efeito da aplicação de vácuo no desempenho de diferentes modelos de gotejadores sob duas condições de textura de solo e posicionados de modo subsuperficial.

\section{Material e Métodos}

O experimento foi conduzido em uma bancada de ensaios de $11 \mathrm{~m}$ de comprimento por $4 \mathrm{~m}$ de largura e 5,80 $\mathrm{m}$ de altura, instalada no Laboratório de Irrigação do Departamento de Engenharia Rural, da Escola Superior de Agricultura Luiz de Queiroz - ESALQ/USP, situada no município de Piracicaba, SP.

O sistema de aplicação permitiu a recirculação da solução aplicada conforme o seguinte esquema: reservatório $\rightarrow$ gotejadores $\rightarrow$ telha $\rightarrow$ calha $\rightarrow$ reservatório.

Os 23 modelos de gotejadores utilizados no ensaio estão descritos na Tabela 1 .

Após prévia secagem e destorroamento os solos utilizados no experimento foram passados em peneiras com abertura de malha de $2 \mathrm{~mm}$ e submetidos a análise textural (EMBRAPA, 2006) apresentados na Tabela 2.

Pequenas bolsas cilíndricas com bidim foram feitas nas dimensões $20 \times 9 \mathrm{~cm}$ e presas por uma extremidade à linha de gotejadores onde, posteriormente, se colocou o solo e, utilizando-se de lacres de plástico, fechou-se a outra extremidade formando-se invólucros com solo (Figura 1).

Foram consideradas parâmetros de avaliação as vazões dos gotejadores medidas antes e depois da instalação dos invólucros com solo.

Inicialmente, foram medidas as vazões de 20 gotejadores em duas linhas laterais (10 gotejadores por linha lateral) de cada modelo de gotejador ensaiado sem a presença dos “invólucros 
Tabela 1. Características dos gotejadores ensaiados

\begin{tabular}{|c|c|c|c|c|}
\hline Identificação & Fabricante & Modelo & $\begin{array}{l}\text { Vazão } \\
\left(L^{-1}\right)\end{array}$ & Fluxo \\
\hline 1 & Naan & Naan Tif & 1,60 & ${ }^{*} \mathrm{C}$ \\
\hline 2 & Naan & Naan Paz & 2,00 & C \\
\hline 3 & Naan & Naan PC & 2,10 & $* * \mathrm{AC}$ \\
\hline 4 & Naan & Naan PC & 3,80 & $A C$ \\
\hline 5 & Plastro & Hydrogol & 2,30 & C \\
\hline 6 & Netafim & Ram & 2,30 & $A C$ \\
\hline 7 & Plastro & Hydro PC & 2,00 & $A C$ \\
\hline 8 & Plastro & Hydro PC & 2,20 & $A C$ \\
\hline 9 & Plastro & Hydro PCND & 2,35 & $A C$ \\
\hline 10 & Plastro & Hydro Drip & 2,00 & C \\
\hline 11 & Carborundun & Carbodrip & 2,00 & $A C$ \\
\hline 12 & Netafim & Tiran & 2,05 & C \\
\hline 13 & Irrimon & Twin Plus & 1,80 & $A C$ \\
\hline 14 & Irrimon & Vip Line & 3,60 & $\mathrm{AC}$ \\
\hline 15 & Irrimon & Irridrip Plus & 2,50 & $A C$ \\
\hline 16 & Netafim & Super Typhoon & 2,00 & C \\
\hline 17 & Petroísa & Azud & 1,40 & C \\
\hline 18 & Toro AG & Drip In PC & 2,50 & $A C$ \\
\hline 19 & Naan & Petrodrip & 1,50 & C \\
\hline 20 & Amanco & Carborundum $\mathrm{CD} / \mathrm{AC}$ & 2,30 & $A C$ \\
\hline 21 & Irriloc & Integral & 1,10 & C \\
\hline 22 & Netafim & Dripnet & 1,60 & $A C$ \\
\hline 23 & Netafim & Uniran & 1,60 & $A C$ \\
\hline
\end{tabular}

${ }^{\star} \mathrm{C}$ - Convencional - Inseridos na linha, com arquitetura interna em labirinto e sem compensação de pressão (variação de vazão ao longo da linha lateral, respeitando-se critérios de dimensionamento); ${ }^{\star \star} \mathrm{AC}$ - Autocompensante - Inseridos na linha, com arquitetura interna em labirinto e presença de membrana de compensação de pressão (vazão aproximadamente constante ao longo da linha lateral, respeitando-se os critérios de dimensionamento)

Tabela 2. Características físicas dos solos utilizados no experimento

\begin{tabular}{cccc}
\hline \multirow{2}{*}{ Solo } & Argila & Silte & Areia \\
\cline { 2 - 4 } & & $\mathbf{g ~ k g}^{-1}$ & \\
Argiloso & 493,4 & 189,6 & 317,0 \\
Arenoso & 200,8 & 79,9 & 719,3 \\
\hline
\end{tabular}
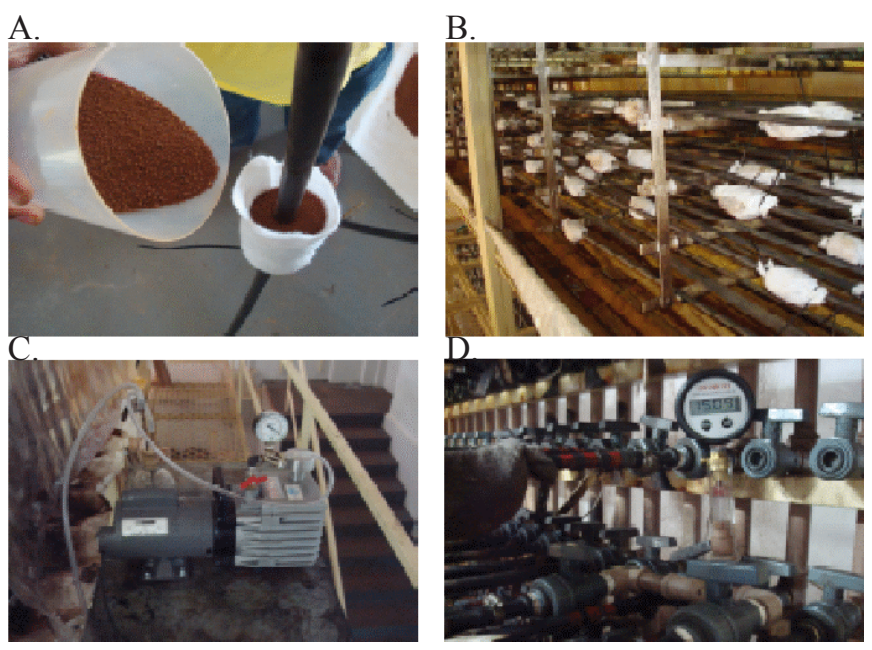

Figura 1. Montagem do experimento $(A, B)$ e detalhes da bomba de vácuo (C) e manômetro (D)

com solo"; prosseguindo, os gotejadores foram envolvidos por "invólucros com solo" e novamente submetidos à medição de vazão; posteriormente foram aplicados os tratamentos que consistiram da aplicação dos níveis de sucção de $-10,-15$, -20 e $-40 \mathrm{kPa}$ em solos de textura arenosa (10 gotejadores na primeira linha lateral) e argilosa (10 gotejadores na segunda linha lateral) em 23 modelos de gotejadores usados com mais de 1 ano de funcionamento.

Antes de cada aplicação de vácuo o sistema de irrigação era ativado durante $30 \mathrm{~min}$ para provocar a saturação do solo; em seguida, cada linha de gotejador era conectada a uma bomba de vácuo elétrica, pelo tempo de $5 \mathrm{~min}$, aplicando-se os diferentes níveis de sucção descritos anteriormente; após três dias da aplicação de cada nível de sucção efetuava-se a leitura da vazão de 10 gotejadores envolvidos pelos "invólucros com solo" em cada linha lateral; só então os valores de sucção foram aplicados em ordem crescente.

O sistema motobomba utilizado nos ensaios era composto por uma bomba centrífuga. O procedimento para leitura individual da vazão dos gotejadores consistiu da pressurização do sistema $(150 \mathrm{kPa})$, posicionamento de recipientes $(1 \mathrm{~L})$ apoiados sobre placas de $\mathrm{PVC}$ de $25 \times 15 \mathrm{~cm}$, nos respectivos gotejadores, com uma defasagem de 5 segundos, retirada sequencial dos recipientes após 5 min com defasagem de 5 segundos, transporte dos recipientes à bancada, pesagem e tabulação dos dados. Na entrada de cada nível do térreo da bancada foi instalada uma tomada de pressão permitindo que a cada medição de vazão fosse checada a pressão e, se necessário, ajustada àquela pré-estabelecida. Para a medição da pressão de serviço na entrada da linha de emissores foi utilizado um manômetro com faixa de leitura de $0-300 \mathrm{kPa}$.

Para obter maior exatidão utilizou-se o método gravimétrico para a determinação do volume coletado de cada emissor expressando-se os valores de vazão em $\mathrm{L} \mathrm{h}^{-1}$ foi utilizada uma balança de precisão certificada com precisão de $0,01 \mathrm{~g}$.

Depois de tabulados os dados efetuaram-se os cálculos da vazão, do coeficiente de variação de vazão e da uniformidade de aplicação de água.

Para determinação da vazão foi utilizada a Eq. 1:

$$
q=\frac{P}{1000 t} 60
$$

em que:

$$
\begin{array}{ll}
\mathrm{P} & \text { - peso da água coletada, } \mathrm{g} \\
\mathrm{t} & \text { - tempo de coleta, min } \\
\mathrm{q} & \text { - vazão do gotejador, } \mathrm{L} \mathrm{h}^{-1}
\end{array}
$$

Para determinação do coeficiente de variação de vazão foi utilizada a Eq. 2:

$$
\mathrm{CV}_{\mathrm{q}}=\frac{\mathrm{s}}{\mathrm{q}} 100
$$

em que:

$$
\begin{array}{ll}
\mathrm{CV}_{\mathrm{q}} & \text { - coeficiente de variação da vazão, } \% \\
\mathrm{~s} & \text { - desvio padrão da vazão dos gotejadores } \\
\mathrm{q} & \text { - vazão média dos gotejadores, } \mathrm{L} \mathrm{h}^{-1}
\end{array}
$$

Para determinação da uniformidade de aplicação de água foi utilizada a Eq. 3:

$$
\mathrm{Ua}=\frac{\mathrm{q}_{25} \%}{\overline{\mathrm{q}}} 100
$$


em que:

\section{Resultados E Discussão}

Ua - uniformidade de aplicação de água, \%

$\mathrm{q}_{25 \%}$ - vazão média de $1 / 4$ dos menores valores de vazão coletados em $\mathrm{L} \mathrm{h}^{-1}$

$$
\overline{\mathrm{q}} \quad \text { - vazão média }
$$

Foi adotado o delineamento inteiramente aleatorizado com dez repetições (gotejadores na linha) e utilização dos testes "F" para análise de variância e Tukey a 0,05 de significância, para comparação de médias e análise de regressão (Barbin, 2003).

Na Tabela 3 tem-se os dados da vazão média dos gotejadores submetidos às diferentes sucções e texturas de solo e teste de média, respectivamente.

A aplicação de diferentes sucções não implicou em redução de vazão para a maioria dos modelos de gotejadores, com exceção dos modelos 10 (arenoso), 12 (arenoso), 16 (ambas as texturas de solo) e 18 (argiloso). No entanto, a

Tabela 3. Vazão média dos gotejadores submetidos a diferentes sucções (kPa) em solo arenoso e argiloso e teste de média, respectivamente

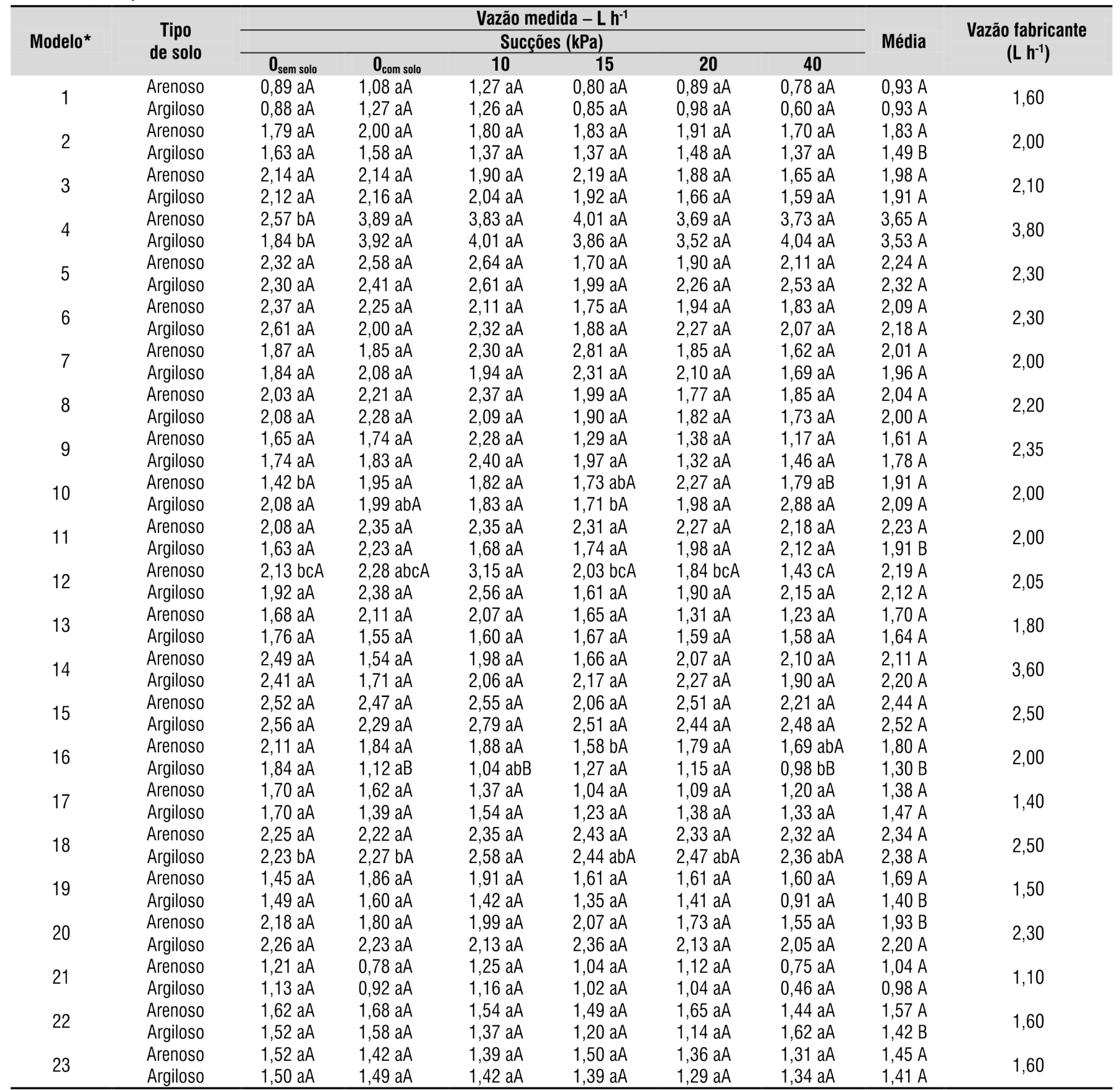

* Para identificação do modelo consulte Tabela 1

$0_{\text {sem solo }}$ - Isento de aplicação de sucção $(0 \mathrm{kPa})$ e vazão medida sem a presença dos invólucros com solo; 0 com solo - Isento de aplicação de sucção (0 kPa) e vazão medida com a presença dos invólucros com solo; *Média com a mesma letra minúscula na linha não indica diferença significativa entre modelos pelo teste Tukey, a 0,05 de probabilidade; **Média com a mesma letra maiúscula na coluna (Arenoso x Argiloso para cada modelo) não indica diferença significativa pelo teste Tukey, a 0,05 de probabilidade 
média dos valores de vazão resultou em redução de vazão em função da textura do solo para os modelos $2,11,16,19$, 20 e 22

Um experimento realizado em laboratório por Liu \& Huang (2009) permitiu caracterizar a percentagem de redução de vazão $\left(\mathrm{q}_{\text {redução }}\right)$ e o coeficiente de variação de vazão $(\mathrm{CV})$ utilizando-se água tratada (AT) e água provinda de estação de tratamento de esgoto (EET) para três modelos de gotejadores inseridos na linha e com arquitetura interna em labirinto (E1: fluxo turbulento; E2: fluxo laminar e E3: autocompensante). Os autores observaram que o uso de água residuária elevou a redução de vazão e o CV para os três modelos de gotejadores sendo que o modelo E2 foi o mais severamente obstruído devido à sua menor dimensão de labirinto; já o emissor E3 em virtude da função antientupimento foi o mais recomendado para irrigação com água residuária contendo elevada alcalinidade e sólidos totais dissolvidos.

Na Tabela 4 observam-se os resultados dos coeficientes de variação de vazão e uniformidade de aplicação de água dos gotejadores submetidos às diferentes sucções e texturas de solo.

Tabela 4. Coeficientes de variação (CV) de vazão e uniformidade de aplicação de água (Ua) dos gotejadores submetidos a diferentes sucções $(\mathrm{kPa})$ em solo arenoso e argiloso

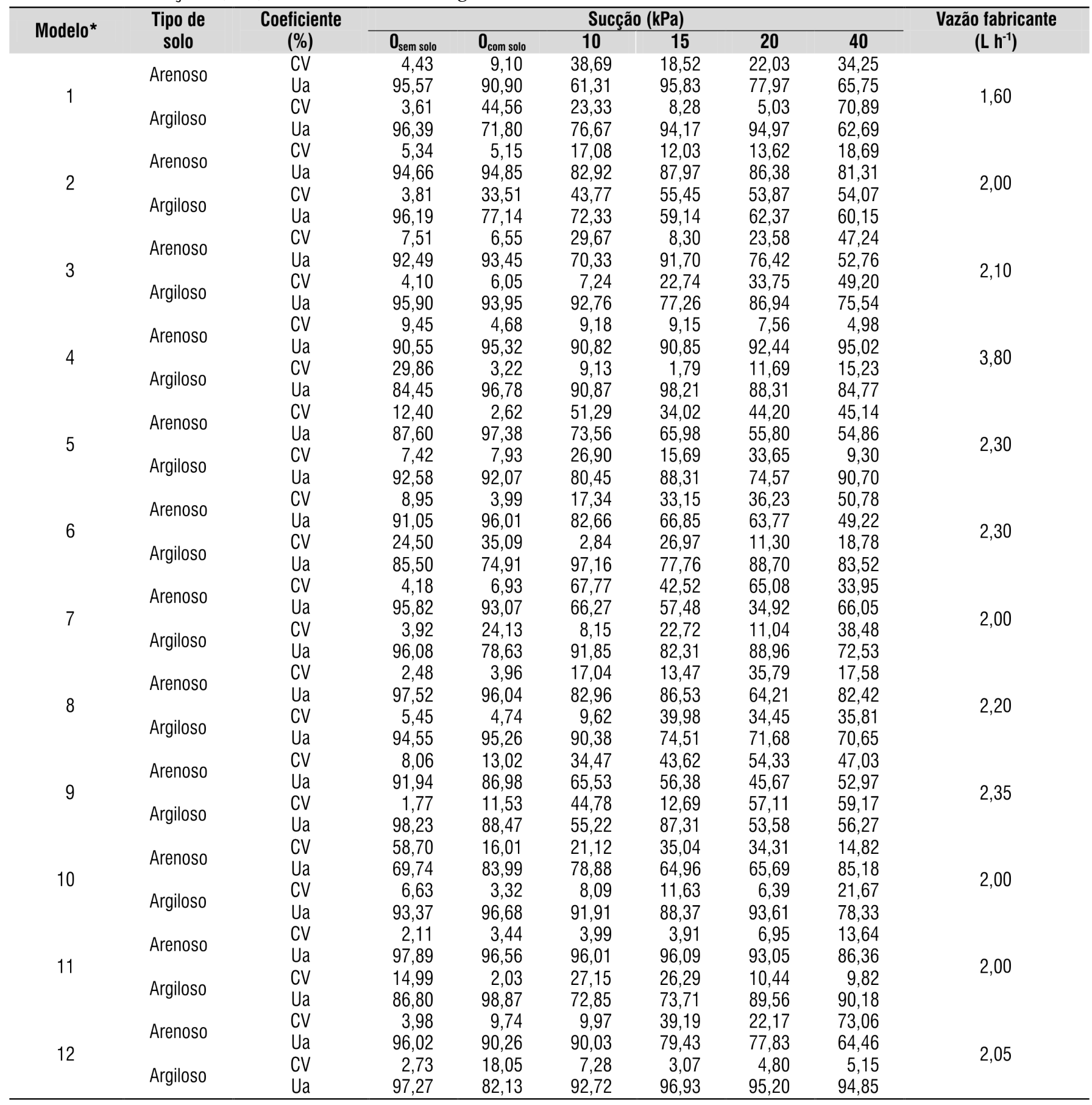


Continuação da Tabela 4

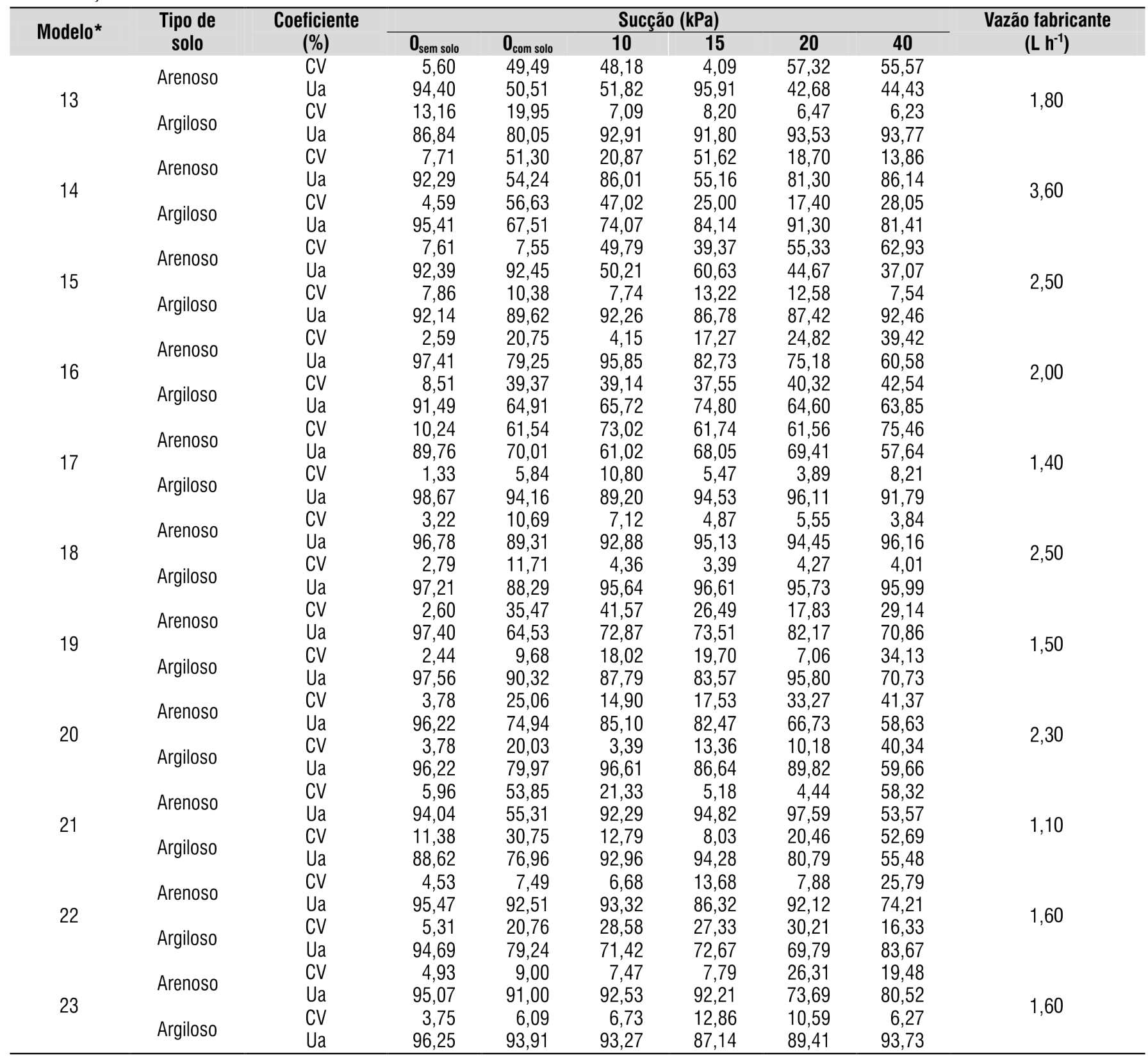

* Para identificação do modelo consulte Tabela 1

$0_{\text {sem solo }}$ - Isento de aplicação de sucção $(0 \mathrm{kPa})$ e vazão medida sem a presença dos invólucros com solo; $0_{\text {com solo }}$ - Isento de aplicação de sucção (0 kPa) e vazão medida com a presença dos invólucros com solo

$\mathrm{Na}$ condição de gotejadores com invólucros com solo e sem aplicação de sucção, o coeficiente de variação de vazão foi inferior a $5 \%(\mathrm{CV}<5 \%)$ apenas para os modelos de gotejadores 4,8 e 11 , em ambas as texturas de solo e para os modelos 5 e 6 (arenoso) e 10 (argiloso). Os maiores valores de CV foram encontrados com a aplicação de sucção de $40 \mathrm{kPa}$, para ambas as texturas, agravando a redução da vazão da maioria dos gotejadores, com exceção dos modelos 4 (arenoso) e 18 (ambas as texturas) em que os valores de $\mathrm{CV}$ foram menores que $5 \%$ após $40 \mathrm{kPa}$ de sucção, recebendo a classificação "bons" conforme ABNT (1986).

Todos os modelos de gotejadores apresentaram distúrbios de vazão em função da inserção do invólucro com solo e das aplicações de sucção, sendo que o modelo 11 na condição de solo arenoso foi o que apresentou comportamento adequado $(\mathrm{CV}<10 \%)$ conforme ABNT (1986).

O modelo 10 (convencional) apresentou aumento de vazão na condição de solo argiloso, conforme o aumento da aplicação de sucção. Na condição de solo arenoso observou-se distúrbio de vazão entre as aplicações de sucção e, comparativamente ao solo argiloso, registrou-se estatisticamente um valor de vazão inferior na condição de sucção $40 \mathrm{kPa}$.

O modelo 12 (convencional) sofreu influência do acréscimo da sucção com redução significativa da vazão na condição de solo arenoso; comportamento semelhante foi observado para o modelo 16 (convencional) na condição de solo argiloso sendo que este modelo diferiu estatisticamente em função da alteração da textura do solo, quando da aplicação de $40 \mathrm{kPa}$ de sucção. 
O modelo 18 (autocompensante) apresentou distúrbios de vazão na condição de solo argiloso observando-se diferença estatística entre a leitura de vazão e se utilizando o "invólucro com solo" sem aplicação de sucção e a leitura de vazão após 10 $\mathrm{kPa}$ de sucção. As demais leituras não diferiram estatisticamente a 0,05 de probabilidade. É provável que isto tenha ocorrido em virtude da acomodação de partículas de solo na área de assentamento da membrana de compensação de pressão, concordando com Coelho et al. (2009).

Resende et al. (2004) observaram, simulando o efeito de cinco níveis de vácuo na vazão dos gotejadores enterrados, maior nível de redução de vazão para os menores níveis de vácuo $(-13$ e $-20 \mathrm{kPa})$. Em níveis de sucção mais elevados $(-53$ e $-80 \mathrm{kPa})$ houve redução na quantidade total de solo succionada. De acordo com os autores a hipótese provável de que isto tenha ocorrido, é devido ao enrijecimento da mistura solo-água imediatamente adjacente ao orifício de saída de água formando um selo físico, que impediu a sucção da pasta de solo que se encontrava mais distante do orifício reduzindo-se, assim, a quantidade total de solo succionada.

A maior redução da uniformidade de aplicação de água (Ua $=37,07 \%$ ) ocorreu com o modelo 15 (autocompensante) recebendo uma classificação ruim para o coeficiente de variação de vazão $(\mathrm{CV}=62,93 \%)$ na condição de solo arenoso e aplicação de $40 \mathrm{kPa}$ de sucção.

$\mathrm{O}$ maior percentual de emissores com entupimento $(\mathrm{CV}>$ $75 \%$ ) foi alcançado pelo emissor 17 (convencional) na condição de solo arenoso e com sucção de $40 \mathrm{kPa}$, comparativamente ao ensaio de vazão inicial (ausência do invólucro com solo e de aplicação de sucção).

$\mathrm{Na}$ Tabela 5 são descritos os parâmetros da análise de regressão para os modelos de gotejadores avaliados.

Tabela 5. Coeficientes de regressão para os modelos de gotejadores

\begin{tabular}{|c|c|c|c|c|c|c|c|}
\hline \multirow{2}{*}{ Modelo" } & \multirow{2}{*}{ Textura do solo } & \multirow{2}{*}{ Variáveis } & \multirow{2}{*}{ Coeficientes } & \multirow{2}{*}{ Erro padrão } & \multirow{2}{*}{$\begin{array}{l}\text { Probabilidade } \\
\text { (a) }\end{array}$} & \multicolumn{2}{|c|}{ Intervalo de confiança (95\%) } \\
\hline & & & & & & Limite inferior & Limite superior \\
\hline \multirow{4}{*}{1} & \multirow{2}{*}{ Arenoso } & $\beta_{0}$ & 0,95686 & 0,07947 & $<0,0001^{\star *}$ & 0,79520 & 1,11850 \\
\hline & & $\beta_{1}$ & $-0,01000$ & 0,02204 & $0,6530^{\text {ns }}$ & $-0,05484$ & 0,03484 \\
\hline & \multirow{2}{*}{ Argiloso } & $\beta_{0}$ & 0,97579 & 0,11882 & $<0,0001^{* *}$ & 0,73400 & 1,21750 \\
\hline & & $\beta_{1}$ & $-0,01536$ & 0,03295 & $0,6443^{\text {ns }}$ & $-0,08240$ & 0,05169 \\
\hline \multirow{4}{*}{2} & \multirow{2}{*}{ Arenoso } & $\beta_{0}$ & 1,85021 & 0,06750 & $<0,0001^{\star \star}$ & 1,71290 & 1,98750 \\
\hline & & $\beta_{1}$ & $-0,00664$ & 0,01872 & $0,7250^{\text {ns }}$ & $-0,04473$ & 0,03144 \\
\hline & \multirow{2}{*}{ Argiloso } & $\beta_{0}$ & 1,63100 & 0,16531 & $<0,0001^{* *}$ & 1,29470 & 1,96730 \\
\hline & & $\beta_{1}$ & $-0,04700$ & 0,04585 & $0,3128^{\text {ns }}$ & $-0,14028$ & 0,04628 \\
\hline \multirow{4}{*}{3} & \multirow{2}{*}{ Arenoso } & $\beta_{0}$ & 2,12471 & 0,12826 & $<0,0001^{\star \star}$ & 1,86380 & 2,38570 \\
\hline & & $\beta_{1}$ & $-0,04900$ & 0,03557 & $0,1777^{\mathrm{ns}}$ & $-0,12138$ & 0,02338 \\
\hline & \multirow{2}{*}{ Argiloso } & $\beta_{0}$ & 2,12700 & 0,12394 & $<0,0001^{\star *}$ & 1,87480 & 2,37920 \\
\hline & & $\beta_{1}$ & $-0,07423$ & 0,03437 & $0,0428^{\star}$ & $-0,14236$ & $-0,00249$ \\
\hline \multirow{4}{*}{4} & \multirow{2}{*}{ Arenoso } & $\beta_{0}$ & 3,42543 & 0,15200 & $<0,0001^{\star \star}$ & 3,11620 & 3,73470 \\
\hline & & $\beta_{1}$ & 0,07486 & 0,04216 & $0,0850^{\text {ns }}$ & $-0,01091$ & 0,16063 \\
\hline & \multirow{2}{*}{ Argiloso } & $\beta_{0}$ & 2,99121 & 0,23217 & $<0,0001^{* *}$ & 2,51890 & 3,46360 \\
\hline & & $\beta_{1}$ & 0,17836 & 0,06439 & $0,0091^{\star *}$ & 0,04735 & 0,30937 \\
\hline \multirow{4}{*}{5} & \multirow{2}{*}{ Arenoso } & $\beta_{0}$ & 2,53250 & 0,22418 & $<0,0001^{\star \star}$ & 2,07640 & 2,98860 \\
\hline & & $\beta_{1}$ & $-0,09750$ & 0,06218 & $0,1264^{\text {ns }}$ & $-0,22400$ & 0,02900 \\
\hline & \multirow{2}{*}{ Argiloso } & $\beta_{0}$ & 2,24100 & 0,13612 & $<0,0001^{* *}$ & 1,96410 & 2,51790 \\
\hline & & $\beta_{1}$ & 0,02529 & 0,03775 & $0,5077^{\mathrm{ns}}$ & $-0,05153$ & 0,10210 \\
\hline & & $\beta_{0}$ & 2,42921 & 0,14860 & $<0,0001^{\star \star}$ & 2,12690 & 2,73150 \\
\hline & Arenoso & $\beta_{1}$ & $-0,11136$ & 0,04121 & $0,0108^{*}$ & $-0,19521$ & $-0,02751$ \\
\hline 6 & & $\beta_{0}$ & 2,28029 & 0,19940 & $<0,0001^{* *}$ & 1,87460 & 2,68600 \\
\hline & Argiloso & $\beta_{1}$ & $-0,03343$ & 0,05530 & $0,5497^{\mathrm{ns}}$ & $-0,14595$ & 0,07909 \\
\hline & & $\beta_{0}$ & 1,95171 & 0,36797 & $<0,0001^{* *}$ & 1,20310 & 2,70030 \\
\hline & Arenoso & $\beta_{1}$ & 0,01886 & 0,10206 & $0,8545^{\text {ns }}$ & $-0,18878$ & 0,22649 \\
\hline 7 & & $\beta_{0}$ & 1,88886 & 0,14421 & $<0,0001^{* *}$ & 1,59550 & 2,18230 \\
\hline & Argiloso & $\beta_{1}$ & 0,02229 & 0,04000 & $0,5812^{\text {ns }}$ & $-0,05909$ & 0,10366 \\
\hline & Arennso & $\beta_{0}$ & 2,19914 & 0,10506 & $<0,0001^{\star \star}$ & 1,98140 & 2,41290 \\
\hline 8 & Arenoso & $\beta_{1}$ & $-0,05143$ & 0,02914 & $0,0868^{\text {ns }}$ & $-0,11071$ & 0,00785 \\
\hline 8 & & $\beta_{0}$ & 2,20450 & 0,13117 & $<0,0001^{\star \star}$ & 1,93760 & 2,47140 \\
\hline & Argiloso & $\beta_{1}$ & $-0,06950$ & 0,03638 & $0,0648^{\text {ns }}$ & $-0,14352$ & 0,00452 \\
\hline & & $\beta_{0}$ & 1,92243 & 0,16624 & $<0,0001^{\star *}$ & 1,58420 & 2,26070 \\
\hline 0 & Arenoso & $\beta_{1}$ & $-0,10271$ & 0,04611 & $0,0328^{\star}$ & $-0,19652$ & $-0,00891$ \\
\hline$y$ & Arailoso & $\beta_{0}$ & 1,95650 & 0,20301 & $<0,0001^{\star \star}$ & 1,54350 & 2,36950 \\
\hline & Argiloso & $\beta_{1}$ & $-0,05750$ & 0,05630 & $0,3146^{\text {ns }}$ & $-0,17205$ & 0,05705 \\
\hline & Arennso & $\beta_{0}$ & 1,93700 & 0,16687 & $<0,0001^{* *}$ & 1,59750 & 2,27650 \\
\hline & Arenoso & $\beta_{1}$ & $-0,00924$ & 0,04628 & $0,8422^{\text {ns }}$ & $-0,10345$ & 0,08488 \\
\hline 10 & & $\beta_{0}$ & 1,91786 & 0,16841 & $<0,0001^{\star \star}$ & 1,57520 & 2,26030 \\
\hline & Argiloso & $\beta_{1}$ & 0,05814 & 0,04671 & $0,2220^{\text {ns }}$ & $-0,03689$ & 0,15317 \\
\hline & Arennsn & $\beta_{0}$ & 2,17450 & 0,05096 & $<0,0001^{* *}$ & 2,07080 & 2,27820 \\
\hline 11 & Arenoso & $\beta_{1}$ & 0,02021 & 0,01414 & $0,1621^{\mathrm{ns}}$ & $-0,00854$ & 0,04897 \\
\hline 11 & & $\beta_{0}$ & 1,83950 & 0,13901 & $<0,0001^{\star \star}$ & 1,55670 & 2,12230 \\
\hline & Argiloso & $\beta_{1}$ & 0,02264 & 0,03856 & $0,5610^{\text {ns }}$ & $-0,05580$ & 0,10108 \\
\hline
\end{tabular}


Continuação da Tabela 5

\begin{tabular}{|c|c|c|c|c|c|c|c|}
\hline \multirow{2}{*}{ Modelo" } & \multirow{2}{*}{ Textura do solo } & \multirow{2}{*}{ Variáveis } & \multirow{2}{*}{ Coeficientes } & \multirow{2}{*}{ Erro padrão } & \multirow{2}{*}{$\begin{array}{l}\text { Probabilidade } \\
\text { (a) }\end{array}$} & \multicolumn{2}{|c|}{ Intervalo de confiança (95\%) } \\
\hline & & & & & & Limite inferior & Limite superior \\
\hline \multirow{4}{*}{12} & \multirow{2}{*}{ Arenoso } & $\beta_{0}$ & 2,60343 & 0,19886 & $<0,0001^{* *}$ & 2,19890 & 3,00800 \\
\hline & & $\beta_{1}$ & $-0,13886$ & 0,05515 & $0,0168^{\star}$ & $-0,25107$ & $-0,02665$ \\
\hline & \multirow{2}{*}{ Argiloso } & $\beta_{0}$ & 2,24693 & 0,11780 & $<0,0001^{* *}$ & 2,00730 & 2,48660 \\
\hline & & $\beta_{1}$ & $-0,04393$ & 0,03267 & $0,1879^{\text {ns }}$ & $-0,11040$ & 0,02254 \\
\hline \multirow{4}{*}{13} & \multirow{2}{*}{ Arenoso } & $\beta_{0}$ & 2,01807 & 0,20164 & $<0,0001^{* *}$ & 1,60780 & 2,42830 \\
\hline & & $\beta_{1}$ & $-0,10650$ & 0,05592 & $0,0656^{\text {ns }}$ & $-0,22028$ & 0,00728 \\
\hline & \multirow{2}{*}{ Argiloso } & $\beta_{0}$ & 1,70786 & 0,05127 & $<0,0001^{\star *}$ & 1,60360 & 1,81220 \\
\hline & & $\beta_{1}$ & $-0,02329$ & 0,01422 & $0,1110^{\text {ns }}$ & $-0,05221$ & 0,00564 \\
\hline \multirow{4}{*}{14} & \multirow{2}{*}{ Arenoso } & $\beta_{0}$ & 2,45564 & 0,22598 & $<0,0001^{\star *}$ & 1,99590 & 2,91540 \\
\hline & & $\beta_{1}$ & $-0,11493$ & 0,06267 & $0,0757^{\text {ns }}$ & $-0,24244$ & 0,01258 \\
\hline & \multirow{2}{*}{ Argiloso } & $\beta_{0}$ & 2,50686 & 0,19719 & $<0,0001^{* *}$ & 2,10570 & 2,90800 \\
\hline & & $\beta_{1}$ & $-0,10086$ & 0,05469 & $0,0742^{\text {ns }}$ & $-0,21212$ & 0,01041 \\
\hline \multirow{4}{*}{15} & \multirow{2}{*}{ Arenoso } & $\beta_{0}$ & 2,65314 & 0,26877 & $<0,0001^{* *}$ & 2,10630 & 3,20000 \\
\hline & & $\beta_{1}$ & $-0,07171$ & 0,07454 & $0,3430^{\text {ns }}$ & $-0,22338$ & 0,07995 \\
\hline & \multirow{2}{*}{ Argiloso } & $\beta_{0}$ & 2,56400 & 0,07968 & $<0,0001^{* *}$ & 2,40190 & 2,72610 \\
\hline & & $\beta_{1}$ & $-0,01343$ & 0,02210 & $0,5476^{\text {ns }}$ & $-0,05839$ & 0,03153 \\
\hline \multirow{4}{*}{16} & Arenoso & $\beta_{0}$ & 1,92707 & 0,10762 & $<0,0001^{\star *}$ & 1,70810 & 2,14600 \\
\hline & Alemuso & $\beta_{1}$ & $-0,04093$ & 0,02985 & $0,1795^{\mathrm{ns}}$ & $-0,10165$ & 0,01980 \\
\hline & & $\beta_{0}$ & 1,67621 & 0,23502 & $<0,0001^{* *}$ & 1,19810 & 2,15440 \\
\hline & Argiloso & $\beta_{1}$ & $-0,12407$ & 0,06518 & $0,0657^{\text {ns }}$ & $-0,25668$ & 0,00854 \\
\hline & & $\beta_{0}$ & 1,70764 & 0,20838 & $<0,0001^{* *}$ & 1,28370 & 2,13160 \\
\hline 17 & Aremoso & $\beta_{1}$ & $-0,11007$ & 0,05780 & $0,0656^{\text {ns }}$ & $-0,22766$ & 0,00751 \\
\hline 17 & & $\beta_{0}$ & 1,68393 & 0,05655 & $<0,0001^{* *}$ & 1,56890 & 1,79900 \\
\hline & Argiloso & $\beta_{1}$ & $-0,07093$ & 0,01568 & $<0,0001^{\star *}$ & $-0,10284$ & $-0,03902$ \\
\hline & Arenoso & $\beta_{0}$ & 2,35279 & 0,04665 & $<0,0001^{\star *}$ & 2,25790 & 2,44770 \\
\hline & AIEIIOSO & $\beta_{1}$ & $-0,00436$ & 0,01294 & $0,7384^{\text {ns }}$ & $-0,03068$ & 0,02196 \\
\hline 18 & & $\beta_{0}$ & 2,28507 & 0,04793 & $<0,0001^{* *}$ & 2,18750 & 2,38260 \\
\hline & Argiloso & $\beta_{1}$ & 0,03050 & 0,01329 & $0,0283^{\star}$ & 0,00345 & 0,05755 \\
\hline & & $\beta_{0}$ & 1,73543 & 0,14019 & $<0,0001^{* *}$ & 1,45020 & 2,02060 \\
\hline & Arenoso & $\beta_{1}$ & $-0,01657$ & 0,03888 & $0,6727^{\text {ns }}$ & $-0,09568$ & 0,06253 \\
\hline 19 & & $\beta_{0}$ & 1,66379 & 0,08910 & $<0,0001^{* *}$ & 1,48250 & 1,84510 \\
\hline & Arglloso & $\beta_{1}$ & $-0,08850$ & 0,02471 & $0,0011^{* *}$ & $-0,13878$ & $-0,03822$ \\
\hline & & $\beta_{0}$ & 2,20836 & 0,12330 & $<0,0001^{\star *}$ & 1,95750 & 2,45920 \\
\hline 20 & Arenoso & $\beta_{1}$ & $-0,09279$ & 0,03420 & $0,0105^{\star}$ & $-0,16240$ & $-0,0232$ \\
\hline 20 & & $\beta_{0}$ & 2,28607 & 0,11160 & $<0,0001^{\star *}$ & 2,05900 & 2,51310 \\
\hline & Argiloso & $\beta_{1}$ & $-0,02736$ & 0,03095 & $0,3832^{\text {ns }}$ & $-0,09030$ & 0,03560 \\
\hline & Arenoso & $\beta_{0}$ & 1,15860 & 0,13187 & $<0,0001^{* *}$ & 0,88360 & 1,42020 \\
\hline 21 & Alemoso & $\beta_{1}$ & $-0,03786$ & 0,03657 & $0,3082^{\mathrm{ns}}$ & $-0,11230$ & 0,03660 \\
\hline 21 & & $\beta_{0}$ & 1,19957 & 0,09586 & $<0,0001^{* *}$ & 1,00460 & 1,39460 \\
\hline & Argiloso & $\beta_{1}$ & $-0,07357$ & 0,02659 & $0,0092^{* *}$ & $-0,12770$ & $-0,01950$ \\
\hline & Arenoso & $\beta_{0}$ & 1,61329 & 0,05537 & $<0,0001^{* *}$ & 1,50060 & 1,72590 \\
\hline 22 & AIEIIUso & $\beta_{1}$ & $-0,01586$ & 0,01536 & $0,3093^{\text {ns }}$ & $-0,04710$ & 0,01540 \\
\hline 22 & Argilosn & $\beta_{0}$ & 1,51871 & 0,11759 & $<0,0001^{\star *}$ & 1,27950 & 1,75790 \\
\hline & AIgilusu & $\beta_{1}$ & $-0,03243$ & 0,03261 & $0,3273^{\text {ns }}$ & $-0,09880$ & 0,03390 \\
\hline & Arenoso & $\beta_{0}$ & 1,59957 & 0,05653 & $<0,0001^{* *}$ & 1,48460 & 1,71460 \\
\hline & Arenoso & $\beta_{1}$ & $-0,04871$ & 0,01568 & $0,0039^{* *}$ & $-0,08060$ & $-0,01680$ \\
\hline 23 & & $\beta_{0}$ & 1,49379 & 0,04922 & $<0,0001^{* *}$ & 1,39360 & 1,59390 \\
\hline & Argiloso & $\beta_{1}$ & $-0,02793$ & 0,01365 & $0,0488^{*}$ & $-0,05570$ & $-0,00015$ \\
\hline
\end{tabular}

\# Para identificação do modelo consulte Tabela 1

* Médias com 0,05 de significância; ** médias com 0,01 de significância; ns não significativo

A análise do coeficiente $\beta_{1}$ da análise de regressão linear apresentou, em função da textura do solo, diferença estatística para os emissores 6, 9, 12, 20 e 23 utilizando-se o solo arenoso e os emissores 3, 4, 17, 18, 19, 21 e 23 para o solo argiloso. O emissor 23 (autocompensante) foi o único que apresentou sensibilidade quanto à análise de regressão para ambas as texturas em função do aumento da aplicação do vácuo na linha gotejadora, apesar deste emissor não ter apresentado variação de vazão média, fato passível de ter ocorrido devido à formação de zonas de estagnação dentro do labirinto do emissor, concordando com Jun et al. (2007) que observaram tal fenômeno em um modelo de emissor com canal trapezoidal em função do tamanho e da densidade das partículas utilizadas no ensaio.

\section{ConclusõEs}

1. O desempenho dos emissores no gotejamento subsuperficial foi influenciado pela textura do solo.

2. De modo geral, em $80 \%$ dos emissores o vácuo de $40 \mathrm{kPa}$ provocou obstrução nos emissores proporcionando redução da vazão, em ambas as texturas de solo. 
3. A maior redução da uniformidade de aplicação de água $(\mathrm{Ua}=37,07 \%)$ ocorreu com o modelo 15 - Irrimon Irridrip Plus 2,5 L h'-1 (autocompensante) recebendo uma classificação ruim para o coeficiente de variação de vazão $(\mathrm{CV}=62,93 \%)$ na condição de solo arenoso e aplicação de $40 \mathrm{kPa}$ de sucção

\section{Literatura Citada}

ABNT - Associação Brasileira de Normas Técnicas. Emissores para sistemas de irrigação localizada - avaliação das características operacionais. São Paulo: ABNT, 1986. 7p. PNBR 12: 02-08-021.

Barbin, D. Planejamento e análise de experimentos agronômicos. 1.ed. Arapongas: Midas, 2003. 208p.

Batista, R. O.; Soares, A. A.; Souza, J. A. R. de; Batista, R. O. Modelos empíricos da irrigação localizada com esgoto sanitário tratado. Engenharia na Agricultura, v.16, 369-377, 2008.

Camp, C. R. Subsurface drip irrigation: A review. Transaction of the ASAE, v.41, p.1353-1367, 1998.

Capra, A.; Scicolone, B. Emitter and filter for wastewater reuse by drip irrigation. Agricultural Water Management, v.68, p.135-149, 2004.

Capra, A.; Scicolone, B. Recycling of poor quality urban wastewater by drip irrigation systems. Journal of Cleaner Production, v.15, p.1529-1534, 2007.

Coelho, R. D. Contribuições para a irrigação pressurizada no Brasil. Piracicaba: ESALQ/USP, 2007. 192p. LivreDocência

Coelho, R. D.; Santos, J. L. C. dos; Castiblanco, C. J. M.; Teixeira, M. B. Suction of soil particles under vacuum conditions in subsurface drip irrigation: Comparative test of emitters. Nevada: ASABE, 2009. 17p.

Dalri, A. B.; Cruz, R. L. Efeito da freqüência de irrigação subsuperficial por gotejamento no desenvolvimento da cana-de-açúcar (Saccharum spp.). Irriga, v.7, p.29-34, 2002.

Dalri, A. B.; Cruz, R. L. Produtividade da cana-de-açúcar fertirrigada com $\mathrm{N}$ e $\mathrm{K}$ via gotejamento subsuperficial. Engenharia Agrícola, v.28, p.516-524, 2008.

EMBRAPA - Empresa Brasileira de Pesquisa Agropecuária. Sistema brasileiro de classificação de solos. 2.ed. Rio de Janeiro: Ministério da Agricultura e do Abastecimento, 2006. 306p.
Faria, L. F.; Coelho, R. D.; Resende, R. S. Variação de vazão de gotejadores de fluxo normal enterrados na irrigação de café. Engenharia Agrícola, v.24, p.589-602, 2004.

Gomes, E. P.; Sousa, A. P. Produtividade da alface (Lactuca sativa L.) em função dos valores de lâminas de água aplicados por gotejamento superficial e subsuperficial. Irriga, v.7, p.35-41, 2002.

Jun, Z.; Wanhua, Z.; Yiping, T.; Zhengying, W.; Bingheng, L. Numerical investigation of the clogging mechanism in labyrinth channel of the emitter. International Journal for Numerical Methods in Engineering, v.70, p.1598-1612, 2007.

Liu, H.; Huang, G. Laboratory experiment on drip emitter clogging with fresh water and treated sewage effluent. Agricultural Water Management, v.96, p.745-756, 2009.

Marques, P. A. A.; Frizzone, J. A.; Teixeira, M. B. O estado da arte da irrigação por gotejamento subsuperficial. Colloquium Agrariae, v.2, p.17-31, 2006.

Resende, R. S.; Coelho, R. D.; Leal, M. de L. da S.; Mata, S. S. da. Suscetibilidade à intrusão radicular de gotejadores convencionais na irrigação subsuperficial de cana-de-açúcar. Irriga, v.9, p.150-165, 2004.

Sanchez-Martín, L.; Meijide, A.; Garcia-Torres, L.; Vallejo, A. Combination of drip irrigation and organic fertilizer for mitigating emissions of nitrogen oxides in semiarid climate. Agriculture, Ecosystems and Environment, v.137, p.99-107, 2010.

Silva, W. L. C.; Giordano, L. B.; Marouelli, W. A.; Fontes, R. R.; Gornat, B. Response of six processing tomatoes cultivars to subsurface drip fertigation. Acta Horticulturae, v.487, p.569-573, 1999.

Solomon, K. H. Global uniformity of trickle irrigation system. Transaction of the ASAE, v.28, p.1151-1158, 1985.

Yavuz, M. Y.; Demirel, K.; Erken, O.; Bahar, E.; Devecıler, M. Emitter clogging and effects on drip irrigation systems performances. African Journal of Agricultural Research, v.5, p.532-538, 2010.

Zhang, J.; Zhao, W.; Wei, Z.; Tang, Y.; Lu, B. Numerical and experimental study on hydraulic performance of emitters with arc labyrinth channels. Computers and Electronics in Agriculture, v.56, p.120-129, 2007. 